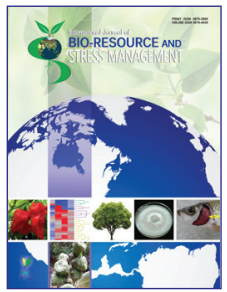

\title{
Level of Satisfaction of Farmers from the Services Provided by Agricultural Technology and Information Centre (ATIC) Run by Punjab Agricultural University
}

\author{
Davinder Singh*, Rajinder K. Kalra
}

Dept. of Extension Education Punjab Agricultural University, Ludhiana, Punjab (141 001), India

6

Corresponding Author

Davinder Singh

e-mail: sdavinder.singh2@gmail.com

Citation: Singh and Kalra, 2019. Level of Satisfaction of Farmers from the Services Provided by Agricultural Technology and Information Centre (ATIC) Run by Punjab Agricultural University. International Journal of Bio-resource and Stress Management 2019, 10(5):575-579. HTTPS://DOI.ORG/10.23910/ IJBSM/2019.10.5.2032

Copyright: (c) 2019 Singh and Kalra. This is an open access article that permits unrestricted use, distribution and reproduction in any medium after the author(s) and source are credited.

Data Availability Statement: Legal restrictions are imposed on the public sharing of raw data. However, authors have full right to transfer or share the data in raw form upon request subject to either meeting the conditions of the original consents and the original research study. Further, access of data needs to meet whether the user complies with the ethical and legal obligations as data controllers to allow for secondary use of the data outside of the original study.

Conflict of interests: The authors have declared that no conflict of interest exists.

\begin{abstract}
ATIC is a "single window" support system linking the various units of research institutions with end users (farmers) in decision making and problem solving exercises. An attempt was made to assess the level of satisfaction of beneficiaries from different services provided by Agricultural Technology and Information centre (ATIC) run by Punjab Agricultural University. A sample of 200 farmers was selected from the two purposively selected districts (Ludhiana and Fazilka) of Punjab from where maximum number of farmers had visited ATIC during the period of June 2011 to December 2013. The findings revealed that a large majority of the farmers were satisfied with the various aspects under the advisory/ diagnosis services i.e. experts behaviour, communication skills of experts, sample diagnosis, technical knowledge of the experts, interest of experts in advisement, time taken to solve problem, expert guidance and language of experts. Majority of the respondents were satisfied with farm literature/publications services, helpline services and technological products provided by the ATIC. Small number of farmers were not satisfied with timing of helpline, price of seed, availability of seed/planting material. Regarding the overall satisfaction towards ATIC services, findings of the study revealed that more than half $(54.5 \%)$ of the farmers had "high" level of satisfaction while one third (33\%) of the farmers had "medium" level of satisfaction. These findings will provide useful guidance to the ATIC for designing effective extension strategy for delivering the services to the farmers in better and efficient way.
\end{abstract}

Keywords: Agricultural technology and information centre (ATIC), satisfaction, services

\section{Introduction}

The research-farmer linkages mediated by the extension system played a crucial role in the advancement of food security through the green revolution in India in the 60s and 70s (Chaudhary et al., 2011). In India, special attention was paid to development of an agricultural research infrastructure immediately after independence. The Indian Council of Agricultural Research (ICAR) acts as a repository of information and provides consultancy on agriculture, horticulture, resource management, animal sciences, agricultural engineering, fisheries, agricultural extension, agricultural education, home science, and agricultural communication (Malhan and Rao, 2007). But a gap between extension and farmers is becoming broader due to lack of basic infrastructures and facilities, trained human resource, and funding for operating costs (Elias et al., 2016). For

\section{Article History}

RECEIVED in $04^{\text {th }}$ September 2019 RECEIVED in revised form $26^{\text {th }}$ October 2019 ACCEPTED in final form $30^{\text {th }} 0$ ctober 2019 
research to be more relevant to the farmers there is a need to create a participatory approach that emphasizes agricultural research and extension linkage and allows farmers to choose appropriate technologies from research stations, thereby eliminating the perception that extension system is separate from the research system (Thomas, 2012). Linking agricultural extension service to farmers can be defined as relations that bring into play a service provider and a farmer, for the purpose of transforming the state of a medium that does not belong to the service provider (Laurent et al., 2006). Some studies revealed that the linkages among the stakeholders were not strong enough and their participation in the existing linkage mechanisms was also less leading to adoption gaps in the recommendations on various technologies (Kaur and Kaur., 2013). It is possible to find a solution to this situation by using the potential of information and communication to meet the location specific information needs of the farmers (Santha et al., 2011). So increase the linkages between farmers and scientists, ATIC was established in 1999 with the aim to deliver technology to farmers under "Single Window Delivery System" in Punjab Agricultural University (PAU). The Agricultural Technology Information Centre (ATIC) is a single window support system linking the various units of research institution with both the intermediary users and end users (farmers) with decision making and problem solving exercise (Anonymous, 2019a). Timely and efficacy supply of quality inputs and services to farmers is a pre-requisite for increasing production (Chaturvedani et al., 2016). In general, the evidence on the impact of extension services on farmer's productivity and technological adoption is positive (CerdánInfantes et al., 2008).

Farmers visit ATIC for redressal of their field problems and bring plant samples for diagnosis. The experts from entomology, plant pathology, soil science and agronomy provide advisory service regarding their respective fields in the centre. Agricultural advisory services are a vital element of the array of market and non-market entities and agents that provide critical flows of information that can improve farmers' and other rural peoples' welfare (Anderson, 2008). The activities undertaken at ATIC include advisory services, sale of technological products, farm literature, plant clinic services and helpline (Anonymous, 2019b). Besides diagnosis of sample, these center provides package of recommendations to farmers, delivering remedial measures in diverse plant health problems based on actual diagnosis of plant samples, popularizing the integrated pest management technology among farmers, carrying out field visits for 'On the Spot' diagnosis of complex field problems and issuing press releases suggesting remedies to combat the outbreaks of pests/diseases and nutritional disorders. In addition clinic is responsible for reorientation of research programmes by providing feedback to scientists regarding the appearance of new plant disorders and regarding the extent of implementation of technologies at the farmers' fields (Pandey and Solanki, 2014). Understanding the satisfaction and extent of access to various services is important to develop appropriate policies and programs for improving service availability and accessibility in rural areas (Sakthivel et al., 2011). An attempt was made in this study to assess the level of satisfaction of beneficiaries from different services provided by ATIC run by Punjab Agricultural University. Satisfaction or dissatisfaction is client's judgment on quality/quantity of service in all its aspect (Chaturvedani et al., 2016). Farmer's satisfaction and expectations are correlated with each other (Salehi and Heydari, 2012). The findings of the study will provide useful guidance to the ATIC for designing effective extension strategy for delivering the services to the farmers in better and efficient way and a feedback to orient the research as well as extension system of Punjab Agricultural University. The study will also be helpful in bringing improvements in the provision of services and guidance by the scientists of ATIC.

\section{Materials and Methods}

A multistage sampling design was used for the selection of the respondents. A list of farmers who visited Agricultural Technology Information Centre/Farmers Service Centre, PAU Ludhiana during the period of June 2011 to December 2013 was collected from the office of Directorate of Extension Education PAU, Ludhiana. A district wise list of the farmers who visited the ATIC was prepared. The total number of farmers who visited the Plant Clinic was 5359. Two districts were selected purposively from where the maximum number of farmers had visited the ATIC i.e. Ludhiana (1484) and Fazilka (396). A total sample of 200 farmers was selected from the selected districts based on the probability proportional to number of the farmers visited from each district. All the four scientists and four service providers were also included in the sample. For the present study services referred to the various types of services (advisory/diagnosis services, sale of technological products, farm literature, plant clinic services and helpline facility) provided by ATIC. Satisfaction was operationalized as the extent to which the farmers were satisfied with the various services provided by ATIC. It measured on a three point continuum i.e. satisfied, somewhat satisfied, not satisfied and score of 2, 1 and zero were assigned respectively.

\section{Results and Discussion}

\subsection{Satisfaction of the farmers regarding the advisory/ diagnosis services}

Data in Table 1 revealed that more than $90 \%$ of the farmers were satisfied with the various aspects under the advisory/diagnosis services i.e. expert behaviour (100\%), communication skills of expert $(98.44 \%)$, sample diagnosis (94.81\%), technical knowledge of the expert (93.75\%), interest of expert in advisement (93.23\%), time taken to solve problem (92.19\%), expert guidance (90.63\%) and language of expert $(90.10 \%)$. While in the case of availability of experts, $80.73 \%$ of the farmers were satisfied and $19.27 \%$ were somewhat satisfied for the same. 


\begin{tabular}{|c|c|c|c|c|c|c|c|}
\hline \multirow[t]{2}{*}{ SI. No. } & \multirow[t]{2}{*}{ Advisory/diagnosis Service } & \multicolumn{2}{|c|}{ Satisfied } & \multicolumn{2}{|c|}{ Somewhat satisfied } & \multicolumn{2}{|c|}{ Not satisfied } \\
\hline & & $f$ & $\%$ age & $f$ & $\%$ age & $f$ & $\%$ age \\
\hline 1. & Technical knowledge of the expert & 180 & 93.75 & 12 & 6.25 & - & - \\
\hline 2. & Communication skills & 189 & 98.44 & 3 & 1.56 & - & - \\
\hline 3. & Time taken to solve problem & 177 & 92.19 & 15 & 7.81 & - & - \\
\hline 4. & Availability of expert & 155 & 80.73 & 37 & 19.27 & - & - \\
\hline 5. & Interest of expert in advisement & 179 & 93.23 & 13 & 6.77 & - & - \\
\hline 6. & Expert guidance & 174 & 90.63 & 18 & 9.38 & - & - \\
\hline 7. & Expert behaviour & 192 & 100 & - & - & - & - \\
\hline 8. & Language of expert & 173 & 90.10 & 19 & 9.90 & - & - \\
\hline 9. & Sample diagnosis & 182 & 94.80 & 10 & 5.21 & - & - \\
\hline
\end{tabular}

It indicated that most of the farmers were satisfied with the various aspects of advisory/diagnosis services. The results were in track with the findings of Kalra and Kumar (1995), Sharma (1999) and Bansal (2009).

3.2. Satisfaction of the farmers regarding the farm literature/ publications
The data in Table 2 indicated that majority (94\%) of the farmers were satisfied with the content of farm literature whereas $88 \%$ were satisfied with the usefulness of the content.

In case of importance of subject matter about $78 \%$ of the farmers were satisfied while $16.5 \%$ were somewhat satisfied. A large majority of the farmers (92.5\%) were satisfied with

Table 2: Satisfaction of the farmers regarding farm literature/publications supplied by ATIC

\begin{tabular}{|c|c|c|c|c|c|c|c|}
\hline \multirow[t]{2}{*}{ SI. No. } & \multirow[t]{2}{*}{ Farm Literature } & \multicolumn{2}{|c|}{ Satisfied } & \multicolumn{2}{|c|}{ Somewhat satisfied } & \multicolumn{2}{|c|}{ Not satisfied } \\
\hline & & $f$ & $\%$ age & $f$ & $\%$ age & $\mathrm{F}$ & $\%$ age \\
\hline 1. & Content of farm literature $(n=200)$ & 188 & 94.00 & 2 & 1.00 & 10 & 5.00 \\
\hline 2. & Usefulness of content $(n=200)$ & 176 & 88.00 & 14 & 7.00 & 10 & 5.00 \\
\hline 3. & Importance of subject matter $(n=200)$ & 157 & 78.50 & 33 & 16.50 & 10 & 5.00 \\
\hline 4. & Suitability of content and title $(n=200)$ & 185 & 92.50 & 5 & 2.50 & 10 & 5.00 \\
\hline 5. & Timely delivery of publication $(n=98)$ & 66 & 67.34 & 6 & 6.12 & 26 & 26.53 \\
\hline 6. & Periodicity $(n=98)$ & 90 & 91.83 & 8 & 8.16 & 0 & 0.00 \\
\hline
\end{tabular}

suitability of content and title of the publication. The data further revealed that $67.34 \%$ of the farmers were satisfied with timely delivery of publications while $26.53 \%$ were not satisfied. It may be due to untimely reach of publication of monthly magazines to the farmers. Majority of the farmers (91.83\%) were found satisfied regarding the periodicity of the monthly magazine. The findings of the study were in conformity with those of Hnumanaikar et al. (2011).

3.3. Satisfaction of the farmers regarding the helpline Services

The data presented in Table 3 indicated that all the farmers were satisfied with the helpline service provided by ATIC. An equal percentage of the farmers (96.26\%) were satisfied with the time taken to solve the problem through helpline service, knowledge of expert, understandability of advice given by experts and availability of experts on the helpline. The data further revealed that $82.24 \%$ of the farmers were satisfied with the language of the expert through the helpline service while $17.76 \%$ were somewhat satisfied. In case of timing of helpline service, $57.27 \%$ of the farmers were satisfied while
$37.61 \%$ were somewhat satisfied and $5.13 \%$ of the farmers were not satisfied. The findings are in line with the study of Anupama (2005). 3.4. Satisfaction of the farmers regarding the technological
products

The satisfaction level of the farmers regarding the technological products was observed under different categories seed, planting material, bio-products and food technology related products (Table 4). Regarding seed as a technological product the data revealed that nearly half of the farmers (47.64\%) were satisfied with the availability of the seed. About 34.03 per cent and $18.32 \%$ of the farmers were somewhat satisfied and not satisfied respectively with the availability of the seed. It is due to the fact that pulses and vegetable seeds are less available at ATIC. About $75 \%$ of the farmers were satisfied with quality of the seed, while $20.94 \%$ were not satisfied with quality of seed mainly due to vegetable seeds.

As many as $87.96 \%$ of the farmers were satisfied and $10.47 \%$ 


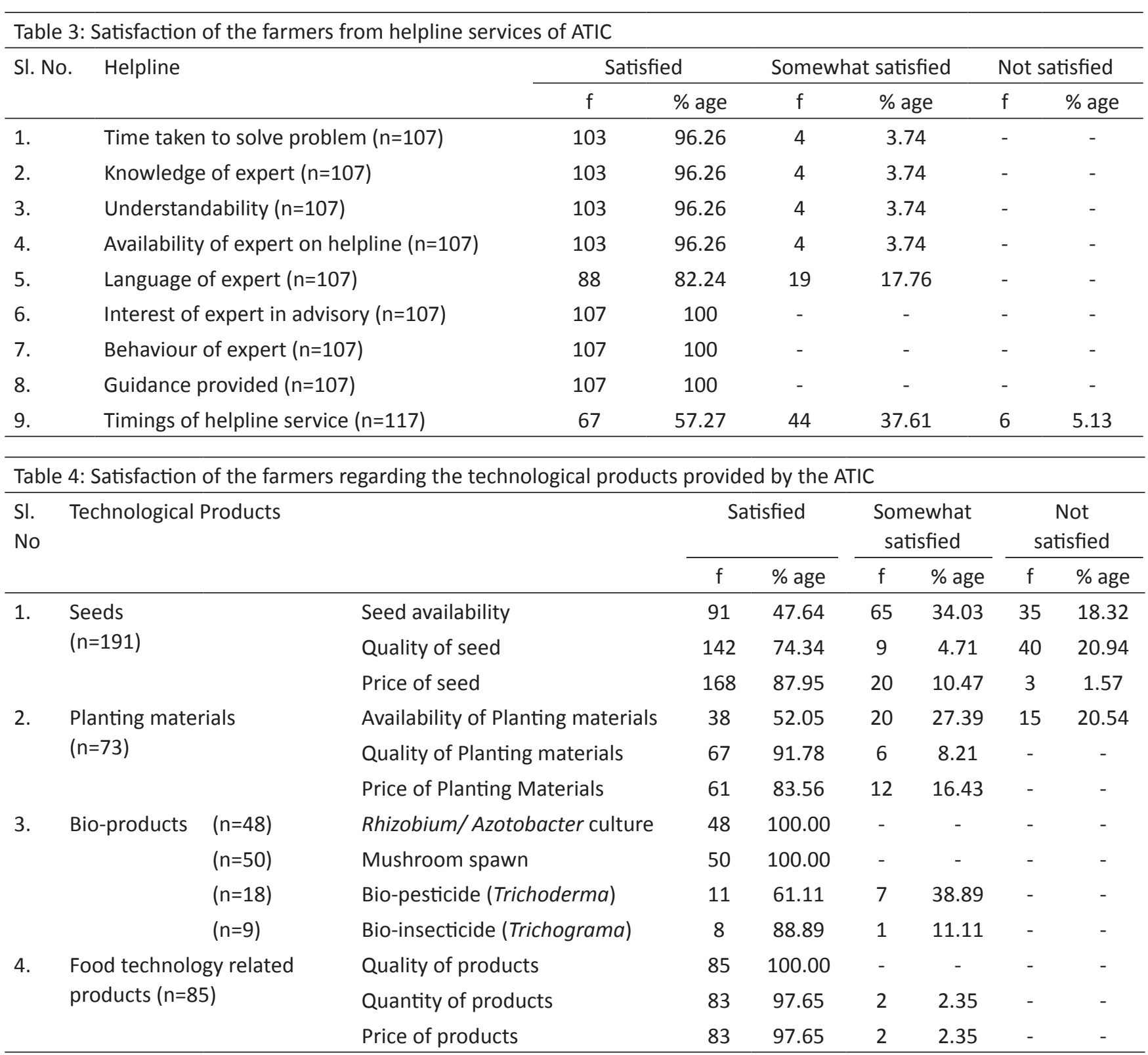

were somewhat satisfied with the price of seed. The data on planting material further revealed that little more than half $(52.05 \%)$ of the farmers were satisfied with the availability of planting material while nearly one fourth (27.39\%) of the farmers were somewhat satisfied. More than 20 per cent were not satisfied with availability of planting materials due to nonavailability of seed sets and cuttings i.e. sugarcane and potato.

A large majority of the farmers $(91.78 \%)$ were satisfied with the quality of planting material. More than eighty per cent $(83.56 \%)$ of the farmers were satisfied and 16.44 per cent were somewhat satisfied with the price of planting material. All the farmers were satisfied with Rhizobium/Azotobacter culture and Mushroom spawn. As many as $88.89 \%$ and $61.11 \%$ of the farmers were satisfied with Bio-insecticide (Trichograma) and Bio-pesticide (Trichoderma), respectively.

Regarding food technology related products all the farmers were satisfied with quality of products whereas an equal percentage of the farmers $(97.65 \%)$ were satisfied with the quantity and price of the products. The results were supported with the studies of Sekhon (2000), Ali (2011) and Khan et al. (2012).

\subsection{Overall satisfaction of farmers}

The data presented in Table 5 indicated that $54.5 \%$ of the farmers had high level of overall satisfaction regarding different services provided by ATIC, whereas 33\% and $12.5 \%$ of the farmers had medium and low level of satisfaction, respectively. It is due to the reason that farmers visited ATIC got satisfactory advice from the experts for the solution of their farm problems. The findings of the study were in conformity with those of Sekhon (2000) and Kumar and Singh (2007), while in contradictory with Chaturvedani et al. (2016). 


\begin{tabular}{llcc}
\hline \multicolumn{4}{l}{ Table 5: Overall satisfaction of farmers to the services of ATIC } \\
\hline SI. No. & Level of satisfaction & $\mathrm{f}$ & \% age \\
\hline 1. & Low (1.54-1.80) & 25 & 12.5 \\
2. & Medium (1.80-1.93) & 66 & 33 \\
3. & High (1.93-2.05) & 109 & 54.5 \\
\hline
\end{tabular}

\section{Conclusion}

The study was an attempt to generate and compile data about satisfaction regarding services provided by Agricultural Technology and Information Centre (ATIC) run by Punjab Agricultural University. It can be concluded that high majority of the farmers were satisfied with advisory/diagnosis services, farm literature/publications services, Helpline Services and technological products provided by the ATIC. More than half and one third of the farmers had high and medium level of overall satisfaction, respectively towards ATIC services.

\section{References}

Ali, M., 2011. Analysis of Farm Services Centres as a new strategy for serving farming community in Khyber Pakhtun Khawa, Pakistan. Proc International Conference on Asia Agriculture and Animal IPCBEE 13, 81-85. IACSIT Press, Singapore.

Anderson, J.R., 2008. Agricultural advisory services. Washington, DC: World Bank.

Anonymous, 2019a. Agricultural Technology Information Centre. Retrieved from https://atariz1.icar.gov.in/ATIC. aspx on 20-09-19

Anonymous, 2019b. ATIC https://www.pau.edu/index. php?_act=manageLink\&DO=firstLink\&intSub ID=34 on 20-09-19.

Anupama, 2005. The extent of utilization of Punjab Agricultural University farmers helpline by farmers and farm women of Punjab. M.Sc. Thesis, Punjab Agricultural University, Ludhiana, India.

Bansal, A., 2009. A study of satisfaction of farmers towards the services provided by Punjab Agricultural University, Ludhiana. M.Sc. Thesis, Punjab Agricultural University, Ludhiana, India.

Cerdán-Infantes, P., Maffioli, A., Ubfal, D., 2008. The impact of agricultural extension services: The case of grape production in Argentina. Office of Evaluation and Oversight (OVE). Inter-American Development Bank. Washington, DC.

Chaturvedani, A.K., Lal, N., Dhruw, K., 2016. Satisfaction Level of Livestock Owner towards Delivery of Veterinary Services. International Journal of Bio-resource and Stress Management, 7(6), 1392-1395.

Chaudhary, S., Clause, M.H., Clause, R., Guntuku, D., 2011. Extension 3.0: The Use of Mobile Phones to Design Farmer-Centered Extension Services. http:// extensionconference2011.cta.int/ sites/default/ files/Extension\%20Conference_Abstracts_Tools.pdf. Retrieved on 15.11.2013
Elias, A., Nohmi, M., Yasunobu, K., 2016. Farmers' Satisfaction with Agricultural Extension Service and Its Influencing Factors: A Case Study in North West Ethiopia. Journal of Agricultural Science \& Technology 18(1), 39-53

Hnumanaikar, R.H., Manjunath, L., Naik, K., 2011. A study on satisfaction level of Kannada farm magazine readers about various components. Karnataka Journal of Agricultural Sciences 24, 474-79.

Kalra, A., Kumar, K., 1995. Opinion of farmers about Farmer's Service Centre of PAU. Agricultural Extension Review 4, 17-19.

Kaur, M., Kaur, R., 2013. Research-Extension-Farmer Linkage system in Punjab Agriculture. International J Advanced Research 1, 699-710.

Khan, I.M., Singh, S., Bangarwa, G.S., Dhanraj., 2012. Impact of ATIC in terms of the satisfaction level of the ATIC beneficiary farmers towards the services of ATIC. Indian Research Journal of Extension Education 1, 245-251.

Kumar, V., Singh, B., 2007. Impact of the Agricultural Technology Information Centre of Central Marine Fisheries Research Institute: Success Cases. Indian Journal of Extension Education 43, 16-19.

Laurent, C., Cerf, M., Labarthe, P., 2006. Agricultural extension services and market regulation: learning from a comparison of six EU countries. Journal of Agricultural Education and Extension, 12(1), 5-16.

Malhan, I.V., Rao, S., 2007, Agricultural Knowledge Transfer in India: a Study of Prevailing Communication Channels. Library Philosophy and Practice.

Pandey, M., Solanki, A., 2014. Utilization of Agricultural Technology Information Centre (ATIC) Facilities by Farm Families in Udham Singh Nagar District (Uttarakhand). International Journal of Science and Research 3, 1011-1014.

Sakthivel, K.M., Khandekar, P., Sasidhar, P.V.K., Narmatha, N., 2011. Access to services: Case of marginal and landless livestock farmers in Tamil Nadu of India. International Journal of Bio-resource and Stress Management 2(1), 112-117.

Salehi, K.H., Heydari, A., 2012. Measuring Villagers' Satisfaction about Performance of Village Government at Shemiranat in Large Lavasan: a Scope for the Use of Models International Journal of Bio-resource and Stress Management 2012, 3(1), 119-121.

Santha, G., Tamilselvi, G., Meenambigai, J., 2011. Extension Education and Rural Development. Agribios, 379-380.

Sekhon, D.S., 2000. A study of service provided by state department of agriculture, Punjab to the farmers of Punjab. M.Sc. Thesis, Punjab Agricultural University, Ludhiana, India.

Sharma, A.K., 1999. An appraisal of services rendered to the farmers by Plant Clinic, PAU Ludhiana. M.Sc. Thesis, Punjab Agricultural University, Ludhiana, India.

Thomas, B., 2012. An Assessment of the Role of Research and Extension Services for Small-scale Crop Farmers in North-Central Namibia. Journal of Agriculture and Biodiversity Research 1, 122-126. 